\title{
From gender bias to gender awareness in medical education
}

\author{
Petra Verdonk • Yvonne W. M. Benschop • Hanneke C. J. M. de Haes • \\ Toine L. M. Lagro-Janssen
}

Received: 17 August 2007/ Accepted: 16 January 2008/Published online: 15 February 2008

(C) The Author(s) 2008

\begin{abstract}
Gender is an essential determinant of health and illness. Gender awareness in doctors contributes to equity and equality in health and aims towards better health for men and women. Nevertheless, gender has largely been ignored in medicine. First, it is stated that medicine was 'gender blind' by not considering gender whenever relevant. Secondly, medicine is said to be 'male biased' because the largest body of knowledge on health and illness is about men and their health. Thirdly, gender role ideology negatively influences treatment and health outcomes. Finally, gender inequality has been overlooked as a determinant of health and illness. The uptake of gender issues in medical education brings about specific challenges for several reasons. For instance, the political-ideological connotations of gender issues create resistance especially in traditionalists in medical schools. Secondly, it is necessary to clarify which gender issues must be integrated in which domains. Also, some are interdisciplinary issues and as such more difficult to integrate. Finally, schools need assistance with implementation. The integration of psychosocial issues along with biomedical ones in clinical cases, the dissemination of literature and education material, staff education, and efforts towards structural embedding of gender in curricula are determining factors for successful implementation. Gender equity is not a spontaneous process. Medical education provides specific opportunities that may contribute to transformation for medical schools educate future doctors for future patients in
\end{abstract}

P. Verdonk $(\bowtie)$

Department of Social Medicine, Faculty of Health Medicine and Life Sciences, University Maastricht, P.O. Box 616, 6200 MD Maastricht, The Netherlands

e-mail: petra.verdonk@socmed.unimaas.nl; petraverdonk@chello.nl

P. Verdonk · T. L. M. Lagro-Janssen

Department of Family Practice, Women's Studies in Medicine, Radboud University Nijmegen Medical Centre, P.O. Box 9101, Internal postal code HAG 117, Nijmegen 6500 HB, The Netherlands

Y. W. M. Benschop

Department of Business Administration, Nijmegen School of Management, Radboud University

Nijmegen, P.O. Box 9108, Nijmegen 6500 HK, The Netherlands

H. C. J. M. de Haes

Department of Medical Psychology J4-404, Academic Medical Centre University of Amsterdam, Meibergdreef 15, Amsterdam 1105 AZ, The Netherlands 
future settings. Consequently, future benefits legitimize the integration of gender as a qualitative investment in medical education.

Keywords Equality · Equity - Gender bias - Gender health issues ·

Gender role ideology · Gender mainstreaming · Gender awareness · Implementation ·

Medical education - Medical curricula

\section{Introduction}

In the past decades, the women's lay movement has criticized the medical profession by stating that women's health care was substandard (e.g. Rosser 1994; Doyal 1995; LagroJanssen and Noordenbos 1997). Critics exposed gender bias in medicine by pointing towards several issues.

Firstly, medicine was accused of being 'gender-blind' by not taking gender under consideration whenever relevant. Secondly, it is said that medicine is 'male-biased' or 'androcentric' because the body of knowledge on health and illness is predominantly about men and their health. A third issue critics pointed to is the way doctors' gender-role ideology negatively influenced treatment and health outcomes. And fourthly, despite the growing body of evidence on gender differences in health, gender inequality is overlooked as a determinant of health.

Interestingly, medicine has not completely ignored gender issues; women's reproductive health issues for instance received a lot of attention. Besides, women patients have been excluded from medical research because of specific female features. Patients have been treated substandard not only because there health needs are not met due to lack of resources or knowledge, but also because they are faced with negative gender stereotypes. Inequalities between men and women are not just reflected within the institution of scientific medicine, but it is stated that medical knowledge and practice also serve to create and maintain gender divisions in society (Doyal 1994 in Wong 1998). Incorporating gender issues in medical education as well as in medical practice, researching and publishing on gender issues without criticizing the backgrounds of this process is not sufficient to change gender bias in practice.

For a long time, gender bias in medicine has hardly been recognized (Zelek et al. 1997). Ruiz and Verbrugge (1997) stated that there are two ways in which health care provision and research may be gender biased. Firstly, there is the assumption that health determinants for women and men are similar when they are not, and secondly, there is the assumption that differences exist when in fact there are similarities (Ruiz and Verbrugge 1997). Gender bias leads to substandard health care for both men and women and to the waste of scarce resources (Doyal et al. 2003). The primarily biomedical focus of health professionals is a consequence of gender-bias in medical training curricula (Jimenez and Poniatowski 2004). Aim of this article is to provide insight in gender bias in medicine and of the role of medical education in the establishment of gender awareness in medicine.

Gender is an essential determinant of social outcomes, including health. Besides, gender can be separated neither from biology nor from other social identifiers as ethnicity, culture, age or social economic class. For instance, it is stated that the largest contributors of ethnic differences are related to social determinants of health such as level of education, socioeconomic disadvantages, and working in jobs which threaten occupational health (Betancourt et al. 2003). Although the impact of ethnic differences or socioeconomic status on health can hardly be underestimated, gender does play a pivotal role within these 
social stratifiers. Differences between men and women are much more influenced by biology than the differences between ethnic or socioeconomic groups (Sen et al. 2002).

Gender health issues can be defined as diseases or conditions unique to, more prevalent in, or more serious in men or in women, including diseases for which manifestations, risk factors, interventions differ in men and in women. Hence, besides the fact that the gaps in knowledge - and the way women and men have been sidelined in specific areas - need to be addressed, awareness of gender issues includes the elaboration of differences and similarities between men and women. Gender issues in health and illness are often interdisciplinary and hence, the biomedical reductionist framework is insufficient to understand these issues. Partial perspectives in this field limit medical knowledge (Hoffman 2000; Rosser 1994). Increasing knowledge of gender issues not only corrects the mentioned historical wrongs, but should also result in more effective interventions (Pinn 2003; Doyal et al. 2003) and the translation of recommendations into practical guidelines is essential (Sen et al. 2002).

Gender issues in the provision of health care exist as well. For instance, results from studies conducted in the United States suggest that female physicians have a more egalitarian style in communicating with patients and feel a stronger sense of responsibility towards disadvantaged patients (e.g. Hall and Roter 1998; Zimmerman and Hill 2000). Meaningful input of women in research and policies is found important because women often have different priorities, needs, interests and resources (UN 2002) which may help to resolve gender bias.

Gender awareness means that health professionals have a gender-sensitive attitude as well as the knowledge of and insight in the full meaning of gender in health and illness. Besides, health providers have the skills to apply their insights to medical practice. In short, gender awareness means that gender is recognised and incorporated as an essential determinant of health and illness. In this paper, firstly the distinction between the concepts of sex and gender and the meaning of these concepts for health and illness are elaborated. Secondly, several components of gender bias are explored. Thirdly, we argue that medical education plays a pivotal role in bridging the gap from gender bias to gender awareness in medicine.

\section{Sex and gender}

In medicine, the terms 'sex' and 'gender' are often used synonymously. However, in women's studies literature-derived from the social sciences-both terms are used as distinctive concepts. 'Sex' refers to biological differences between men and women, i.e. chromosomes, internal and external sex organs and secondary sex characteristics as well as hormonal makeup. 'Gender' refers to how differences between men and women are constructed in different cultures (e.g. Hammarström 2003; Pinn 2003).

In women's studies, biological explanations for differences between men and women are suspect because biology has long been abused to legitimize the submission of women, for instance because women were supposedly ruled by their bodily cycles (Horstman 1995). Lie (2002) argues that the concept of gender was not introduced to question biological difference as such, but rather to question biological explanations for social difference. The distinctive concepts of 'sex' and 'gender' evolved from the nature-culture debate, with the presumptions that sex is unchangeable, where gender is constructed, and as such amenable to change (Brouns 1995). However, it is stated that it is more difficult to change ideas about masculinity than to change hormone levels. The attribution of 
changeability to gender and genetic programmes to sex is challenged by several authors (e.g. Horstman 1995; Lorber and Moore 2002). Recently, evolutionary psychology has proposed biological explanations of behaviour by arguing anew that social constructions may have a biological origin (e.g. Taylor et al. 2000). However, the degree to which a health phenomenon is specifically social or biological cannot always be distinguished (Risberg et al. 2004). For instance, gender differences in responses to pain may be related to physiological mechanisms of the brain or to psychosocial factors or to both (Pinn 2003). Therefore, in medicine it is necessary that we include all features of sex and gender in order to get a clear understanding of health determinants (Phillips 2005).

\section{Gender bias in medicine}

In this section, four different forms of gender bias are elaborated: gender blindness, male bias, gender role ideology and gender inequality. Examples, with a specific focus on depression and coronary heart disease, are used to illustrate the key points of these four types of gender bias.

\section{Gender blindness}

Gender blindness - not taking gender under consideration when it is relevant-is exposed by the fact that women's health issues in other domains besides reproduction have been overlooked. In clinical studies, female patients have been excluded for well-established reasons such as: (1) the confounding effects of female menstrual cycle on test results, thereby increasing complexity and costs of research; (2) the fear that the investigated treatment may affect female fertility or pregnancy, or; (3) a higher incidence of some diseases in men (Clark et al. 2002; Rosser 1994). Nevertheless, expected physiological similarities between men and women led to the extrapolation of research findings conducted in male populations to female patients. Hence, these studies result in medication inadequately tested in women subjects. Rosser states that this does not only ignore the fact that women may respond differently to drugs, it may also lead to less accurate models for male patients (Rosser 1994). She argues that it is possible that the female body with cyclic reproductive hormone levels provides a more accurate human model for most hormones. Bird and Rieker (1999) state that besides the fact that studying men does not generate generalisable results to women, these studies also fail to provide a clear picture of gender similarities in health and illness. Surely, without gender-disaggregated data a genderanalysis cannot even take place (Sen et al. 2002). Sex differences should be placed in their cultural, social and historical context and warrant periodical re-evaluation, because the direction and magnitude of sex differences in morbidity may vary according to the particular symptom or condition and according to patients' life stages (Macintyre et al. 1996; Sen et al. 2002). It should be emphasized that male gender is included into gender-sensitive research as well.

Currently, a large body of evidence exposed sex differences in health and illness. Coronary heart disease (CHD) is among the fields in which an abundance of research has demonstrated differences between men and women (Westerståhl et al. 2003; Mosca et al. 2007). Women are on average 10 years older than men when they manifest heart disease and usually 20 years older at the time of their first myocardial infarction. Many women do not feel themselves at risk for CHD partly due to confusion created by mixed messages from the media (Mosca et al. 2007). In 2004, the American Heart Association (AHA) 
published a first evidence-based guideline for the prevention of heart disease in women which was updated in 2007 (Mosca et al. 2007). Despite the large body of evidence on CHD in women, a recent study exposed that gender differences in coronary heart disease were not addressed in Dutch medical curricula (Verdonk et al. 2006).

\section{Male bias}

Male bias is defined as observer error exposed in medical research which follows from a male perspective and habit of thought (Pinn 2003; Doyal et al. 2003). Male bias has had consequences on the choice and definitions of problems that are studied, the methodology used to collect and interpret data, as well as theories and conclusions drawn from data (Rosser 1994). Therefore, a larger body of knowledge exists in traditionally men's diseases such as coronary heart disease than in traditional women's diseases-besides reproductive health issues-like for instance rheumatism. Disease occurring more often in women is also considered less important. In a recent Norwegian study, physicians and medical students ranked coronary heart disease number one on a list of 38 different diseases from important to unimportant whereas arthritis ranked number 27 (Album and Westin 2008). Low prestige is attached to diseases not located in or around a specific organ, diseases developing slowly instead of hitting abruptly, and with long duration. Characteristics of patients having the disease may play a role in the allocation of prestige: 'the fact that the typical patient is a woman could be among the factors involved' (p. 187). Coronary heart disease is still considered a male disease. In a recent study in primary care conducted in the UK, the view was supported that knowledge about female heart disease is not yet fully integrated into 'received medical wisdom' (Adams et al. 2007). In their study, physicians were shown standardized videotaped vignettes and physicians took account of patients' age when diagnosing CHD symptoms in men but not in women.

Relegating women's health issues to reproductive health and pregnancy-related illness confirmed the social construction of women as mothers and wives (Davis 1988; Nicolette and Jacobs 2000; Searle 1998). For instance, looking from a male point of view in biology led to the dogma that women were seen as the passive recipients and carriers of men's offspring (Fausto-Sterling 2000). On the other hand, the relegation of reproductive health to women's health lead to gaps in evidence-based knowledge on men's reproductive health problems. For instance, there is lacking knowledge of psychosocial aspects of prostate cancer. Contrary to the research of breast cancer and female gender identity, there is little research into the effect of prostate cancer on male gender identity (Kiss and Meryn 2001). As regards mental health, the relegation of women's health issues to mental illness confirmed women's supposedly mentally unfit position (Davis 1988). Moreover, it lead to lacking knowledge of mental illness in men. Despite the robustness of the finding-across cultures, methodologies and instruments-that depression occurs twice as often in women than in men (Bebbington 1996), some authors state that men may be overlooked in depression (Noordenbos 2007). Men may present depressive symptoms differently-or not present their depressive symptoms - and may mask a depression with alcohol abuse. Furthermore, DSM-IV diagnostic criteria may be gender-biased because they describe women's symptoms better than men's. Noordenbos (2007) states that the 2:1 sex ratio is caused by a discrepancy between masculinity beliefs and depressive symptoms; men would rather be diagnosed as burnout than as depressed, because determinants for burnout can be localized outside the individual, e.g. in work demands. In gender blindness, differences between men and women are overlooked because disease in men and women is supposedly 
similar. Male bias is also expressed in the tendency to use men as the standard even in diseases affecting both men and women, but from a different perspective: male bias leads to the treatment of female symptoms as outliers of regular syndromes (Davis 1988; Hoffman 2000; Alexanderson et al. 1998). For instance, symptoms of women with CHD are viewed as atypical even though these symptoms may be more typical for women (Gijsbers van Wijk et al. 1996; Lagro-Janssen and Noordenbos 1997). Women's health concerns such as heart disease, lung cancer, depression and abuse are leading causes of women's death and disability. Nevertheless, Clark states that these topics are not covered well by either general medical journals or even by journals on women's health, although the latter do provide a more balanced coverage addressing social concerns as well as biological and reproductive issues (Clark et al. 2002). Men's health journals are new and studies to their coverage have not been conducted yet.

And finally, critics have stated that male bias lead to medicalisation by pathologising and treating female normal bodily functions and life stages. Examples are the presentation of menopause as a deficiency disease which should be treated with Hormone Replacement Therapy (Gijsbers van Wijk et al. 1996; Davis 1988) or feminist concerns about obstetric technologies (Doyal 1995; Gijsbers van Wijk et al. 1996).

\section{Gender-role ideology}

Gender-role ideology represents a health care worker's attitude towards male and female patients and doctors (Verdonk et al. 2007a). Gender-role ideology plays a role in health care at several levels. First, doctors' gender stereotyping towards patients may be seen as a risk factor for inadequate care. In a qualitative study conducted in Norway, it was found that nurses and physicians' negative attitudes are especially directed towards female hospital patients in viewing them as more demanding because they ask too much information and communicate diffusely (Foss and Sundby 2003). Especially elderly female patients were described with frustration by physicians, because their request for care was at odds with the strive for efficiency. Health conditions of women are more often attributed to uncontrollable and unchangeable factors such as biology and emotions than the same health conditions in men, which are more often attributed to controllable factors such as behaviour (Benrud and Reddy 1998). Although there are negative implications for both genders, women may suffer more from this pattern, for instance when seeking care for 'atypical' cardiac symptoms (Lagro-Janssen and Noordenbos 1997). Situational aspects may elicit this aspect of gender bias. Underdiagnosis of CHD and underreferral to cardiologists was exposed among American medical students' and residents when women presented typical CHD symptoms in the context of stressful life events (Chiaramonte and Friend 2006). Women however present more often than men with atypical symptoms, which means that those findings may underestimate gender bias in CHD diagnosis. In Adams et al. (2007) video-vignette study, doctors were more likely to look for psychological cues and search for psychological explanations for key CHD symptoms in women than for symptoms in men. Possibly, when presenting atypical symptoms, women may be even more disadvantaged.

Secondly, unawareness of gender-specific communication styles may lead to communication problems in the physician-patient relationship (Bylund and Makoul 2002). Research points towards gender differences in the presentation of health complaints with female patients referring more often to their social context than male patients (e.g. Bylund and Makoul 2002) and men referring more often to their body as a technical device (Mansfield et al. 2003). This may result in the perception that women's health problems 
have social or psychological origins and that women are more demanding. For men, undermedicalisation of mental health problems may exist for instance in depression (Noordenbos 2007). With this possibility in mind, the perception that male hospital patients are less difficult to communicate with is disquieting (Kilmartin 2005; Foss and Sundby 2003). Doctors may not perceive men's depressive symptoms because they are not incorporated in the body of 'received' medical knowledge. Gender role ideology is an obstacle for doctors to perceive depression in men; doctors' lacking knowledge a consequence of male bias in research and training.

Thirdly, the pursuit for masculinity or femininity may lead to actual gender differences in health problems. For instance, specific male social roles and expectations as regards risk-taking behaviour may result in disability or premature death or may lead to men's underreport of symptoms or denial of illness, to delay in seeking care, or refusal of treatment (Courtenay 2000; Moynihan 1998; Lorber and Moore 2002; Mansfield et al. 2003; White and Cash 2004; Noordenbos 2007; Christianson et al. 2007). Differences exist in the way masculinities and femininities impact on health. Gender roles and expectations vary greatly across for instance contexts, cultures, socio-economic groups, and age.

Finally, gender stereotyping can be presented as a linguistic issue as well (Bowker 2001). Sexist language is not only a symptom of underlying sexism, but language has the capability of shaping concepts which may lead to bias in the theory itself (Rosser 1994). In a study on medical language for special purpose among professionals, the terminology of infertility is described to establish the nature and current degree of gender insensitivity (Bowker 2001). In some men, the immune system effectively destroys the sperm as soon as they are produced, which is typically described as autoimmunity or sperm antibodies. However, a woman who develops antibodies against her partner's sperm in her cervical mucus has the condition mucus hostility or cervical hostility. There are no reasons why men could not be described as having hostile sperm, or why women could not be described as producing sperm antibodies (Bowker 2001). Gender awareness means that besides establishing an integrative view of gender health issues by addressing biological, reproductive and social issues, gender stereotypes—old and new ones, and towards men and women-need to be targeted as well.

\section{Gender inequality}

Inequality between men and women is a serious barrier for both men and women to reach their full health potential and several gender-based inequities in the provision of health care are revealed (WHO 2001; Sen et al. 2002; Phillips and Ferguson 1999; Gijsbers van Wijk et al. 1996; Lagro-Janssen and Noordenbos 1997). In 1995, objectives towards gender equality were adopted by the United Nations Beijing Platform for Action (UN 1995). For instance, governments need to promote research and disseminate information on women's health (WHO 2001). Objectives mainly focused on women's health involving emotional, social and physical well being and which is determined by the social, the political and economic context of women's lives as well as by biology. Later, it became apparent that health should be viewed in the perspective of gender relations (WHO 2002). Currently, broader processes of change are advocated and gender equality is defined as a developmental aim because it contributes to the achievement of other objectives, such as better quality of care and efficiency (UN 2002; Doyal 2000; Doyal et al. 2003). The risks following from men's pursuit to be masculine, or to avoid being feminine, may not only influence male morbidity and mortality but might have an impact on women's health status 
as well (Sabo 1999). For instance, masculine norms about risk-taking prevent men from adopting safe sex practices which endangers their own as well as women's health. A recent study conducted in Sweden among young women and men between 18 and 24 years old tested negative for HIV revealed that responsibility for testing was a gendered issue (Christianson et al. 2007). For young women, testing seemed 'natural', whereas boys' sense of irresponsibility for testing was viewed as 'masculine'. Young men never considered themselves as transmitters of HIV whereas young women worried about contamination (Christianson et al. 2007). In general, the construction of masculinity does not promote self-nurturing attitudes among males and may, thus, place an unfair burden on women for maintaining men's health as well their own (Sabo 1999). This process is called 'reciprocality'. In positive gendered health synergies, favourable health processes or outcomes are promoted by the pattern of gender relations, whereas unfavourable processes or outcomes are associated with negative gendered health synergies (Sabo 1999).

Gender equality may be defined as the absence of discrimination on the basis of a person's sex in opportunities, in the allocation of resources and benefits, or in access to services (WHO 2002). Gender equity means that gender differences in needs and power should be identified and the imbalance between the genders must be addressed and rectified (WHO 2001). Although equality under the law and in economic opportunities is served best within a sex- and gender-neutral manner, in health care equity means a respect for difference without losing sight on gender inequality (Hoffman et al. 2000; Sen et al. 2002). In the World Health Organizations' 'Gender Policy', rationales for integrating a gender perspective in their work are given (WHO 2002). To contribute to better health for women and men, the integration of gender considerations must become standard practice in all policies and programmes of WHO. Complementary policies towards achieving gender equality in staffing are also necessary. This approach aiming towards gender equity and equality is called 'gender mainstreaming'. Women and men should benefit equally from all aspects of an organisation's activities in which individual talents can be developed irrespective of sex (Doyal et al. 2003; Stevens and van Lamoen 2001). Gender mainstreaming is viewed as mostly effective towards gender equity (WHO 2001).

Women's health advocates as well as the WHO have propelled the incorporation of sex and gender factors in research design and the inclusion of women in clinical studies to provide basic fundamentals for gender-specific health care (e.g. WHO 2001; van MensVerhulst and Moerman 2002; Pinn 2003; Bekker 2003; Phillips 2005; Hammarström 2007). A diversion of scientists with regard to gender, age, ethnicity, class or sexual orientation is necessary to prevent the perspective of one group to bias research design, approaches, subjects, and interpretations (Rosser 1994). Besides, medical language should reflect changing norms (Bowker 2001). And finally, Im and Meleis (2001) state that gender-sensitive theories in medicine are based on the acknowledgment and affirmation of gender equity and diversity, on the premises that women and men are affirmed as individuals and that both genders should have options and control over their own bodies. Gender awareness - a gender-sensitive attitude and knowledge and insight in the full meaning of gender for health and illness-explicitly incorporates the acknowledgement of existing gender inequalities and aims towards gender equity.

Gender mainstreaming in medical education

In a gender-specific medical curriculum students have gained knowledge and insight into the meaning of gender in health and illness and have learnt to apply this insight to medical 
practice (Zelek et al. 1997). The incorporation of gender issues is necessary to establish a gender perspective in medical education, which aims towards gender awareness in future doctors. A gender-specific medical curriculum is a prerequisite for a gender-specific health care and is a catalyst for reform towards social change (e.g. Bickel 2001; Verdonk et al. 2006).

Despite the large body of evidence, for instance in CHD, gender issues do not enter medical practice and education spontaneously. So far, medical curricula have not been transformed nor by the growing research on women's health issues neither by the growing numbers of female students in medical school. Medical education still lacks coverage of issues pertaining to women in teachings about certain disorders (male bias), lack of female subjects in medical research (gender blindness), cross-discipline aspects of women's health (gender inequality) thereby still exposing gender bias (Weisman 2000; Verdonk et al. 2006). Subtle gender bias may be apparent in classroom gender stereotypes and in education material (gender role ideology). For instance, Alexanderson et al. (1998) performed a gender analysis of medical textbooks and concluded that a male norm is apparent and that gender differences are concealed. Medical teachers have a responsibility to select literature and - if necessary - offer complementary teaching material and methods (Alexanderson et al. 1998; Nicolette and Jacobs 2000).

Disregard for gender in the curriculum affects not only health care provision towards patients, but it affects men and women in the workforce as well. Gender sensitizing curricula may affect gender equality in specialties traditionally seen as the domain of men, such as surgery, or traditionally seen as the domain of women, such as paediatrics (Reichenbach and Brown 2004). In addition to curricular issues, medical students learn respect for patients through the way in which gender issues are addressed within their own school (Zimmerman and Hill 2000). These authors state that medical education creates precedents for gender bias by the extent to which there is an atmosphere of respect (or disrespect) towards women and minorities. Indicators for this respect are evidently apparent in medical curricula as well as in the composition of the workforce. In conclusion, gender bias has relevance to medical education and a transformation of values and norms towards gender awareness is necessary (Sen et al. 2002).

Medical education provides specific opportunities that may contribute to transformation; doctors are educated for future patients in all possible social contexts. In the literature, several model programs and course evaluations as regards gender issues have been described (e.g. Rogers and Henrich 2003; Wainer 2003). Furthermore, initiatives on the internet aim to disseminate gender-specific education material, provide web-enabled curricula or formulate objectives for women's health care competencies (e.g. Mans et al. 2006; Gender and Health Collaborative Curriculum Project n.d.; APGO n.d.).

To establish inclusive curricula, several models are proposed for addressing gender and multicultural issues in higher education: (1) a separate-course model as an addition to the existing curriculum; (2) area-of-concentration model for those who aim to work with specific groups; (3) an interdisciplinary model with courses in other disciplines, or; (4) the integration model in which courses are reviewed and modified according to comments from experts in the field (Davis-Russel 2003). The integration model overcomes weaknesses of the other models: it permits intensive study and does not depend on students electing to take the course. But the integration model also the most difficult to implement as it requires commitment of all involved. Integrating gender-gender mainstreaming - in medical education is the strategic weaving of gender issues across medical education, whenever relevant, and tailored to specific settings. 
Although many interdisciplinary topics-such as pharmacology, nutrition, or other social issues as ethnicity, age and economic class-face similar barriers in trying to surmount the boundaries of medical disciplines, implementing gender issues in medical education brings about specific challenges. This is among other reasons due to: (1) institutional resistance to change; (2) uncertainty about which gender issues should be included in a curriculum, and; (3) a lack of practical guidelines for implementation (Henrich 2004). These issues are addressed in the next paragraphs.

\section{Resistance to change}

Gender issues may evoke resistance which is due to political-ideological connotations of gender matters (Verdonk et al. 2005). In a qualitative study of students' resistance to gender issues in teacher education, Titus (2000) distinguished four postures ranging from deny to dismay. Denial is apparent when students feel that they would have noticed from their personal experience that gender inequality existed, and since they do not notice gender inequality, it must not exist. Gender issues may also be discounted within the hierarchical scale of worthwhile knowledge. Distancing is when problems are blamed on an unchangeable factor. Dismay occurs when confusion is overwhelming and no solutions are seen (Titus 2000). A qualitative study conducted in Sweden on medical students' attitudes towards gender issues revealed that including gender in medical curricula meets the needs of female students more than those of male students and that female students found gender issues more interesting and important (Hamberg and Johansson 2006). Likewise, Risberg et al. (2003) found an interaction between gender and specialty as to whether medical teachers found gender important in professional relationships; especially male physicians from the surgical group assessed gender significantly as less important than female physicians.

At the organizational level, it is stated that traditionalists in medical school-who perceive health as the absence of disease-form an obstacle for change. They are perceived to be the greatest barrier for implementing gender issues by preserving boundaries and maintaining traditional beliefs of reductionism and objectivity (Searle 1998; Nicolette and Jacobs 2000). The attitude that medical knowledge is neutral and objective however does not hamper the uptake of (biomedical) sex difference, but these issues indeed risk to be cut loose from their gendered origins. 'Objective' biomedical aspects of gender issues may then disappear into seemingly neutral but superficial and biased knowledge (Henrich 2004; Verdonk et al. submitted). Therefore, it is important that the incorporation of gender issues is advanced by the intervention of current leadership in medical schools (Donoghue 2000; Verdonk et al. 2006). Institutional commitment is not only indicated by a high level of support by the dean and senior faculty, but also by the allocation of financial resources and time (Beck Weiss et al. 2000; Nicolette and Jacobs 2000).

\section{The domains}

Medical schools need a clearer insight in which gender issues are of specific relevance, for instance in coronary heart disease; pharmacology; domestic and sexual violence, sexuality and sexual problems; mental health issues like depression, posttraumatic stress disorder, anxiety disorders, and substance abuse, as well as; gender differences in communication styles and the intersection of gender with other social identifiers such as ethnicity or 
socioeconomic status (e.g. Verdonk et al. 2005). These issues are major public health issues and gender plays a role at several levels, biologically and psychosocially. Obviously, relevant sex and gender differences apply to all medical disciplines (Beck Weiss et al. 2000). Still, they are specifically relevant in some. Besides the obvious link between women's health issues and gynaecology/obstetrics, several other disciplines are mentioned in the literature as of specific suitability to communicate the importance of gender issues to students: (1) primary health care because of its multidisciplinary character (Weisman 2000); (2) internal medicine because it serves as a foundation for virtually all other clinical specialties and has a highly visible and valued place in medical school curricula (Nicolette and Jacobs 2000); (3) paediatrics because this would emphasize a social view of health (Searle 1998); (4) psychiatry because of the high prevalence and failures in recognition and treatment of psychiatric disorders (Brodkey and Shaw 2002); or (5) the clinical clerkships because focusing on women's issues in one specialty runs the risk of linking issue recognition and problem solving to the domain of that specialty (Magrane et al. 2000). The integration of gender issues and women's health issues in every discipline without having an overview on the whole curriculum runs the risk of transforming a gender gap in education into a gender overlap. Monitoring the issues addressed and at which moment in the curriculum is necessary but difficult. This problem however is not unique to gender issues and applies to other interdisciplinary issues as well.

\section{Practical guidelines for implementation and facilitating factors}

Besides discussing gender issues at a political level with faculty leadership, schools also need practical assistance with implementation. As mentioned, gender issues cut across disciplines. A gender-specific curriculum incorporates free-standing electives as well as an interdisciplinary curriculum, in which several disciplines take the lead in addressing gender issues within their domain (Magrane et al. 2000). Psychosocial issues along with biomedical ones can be incorporated in clinical cases and provide insight in the multidisciplinary aspects of gender issues in health (Beck Weiss and Levison 2000; Verdonk et al. 2005). Total curriculum reforms are not necessary, but institutions with case-based learning can more easily revise and write inclusive cases (Verdonk et al. 2006; Beck Weiss et al. 2000). Gender issues need to be incorporated into learning objectives to ensure minimal standards of students' knowledge, attitudes and skills (APGO n.d.).

The integration of psychosocial aspects of gender issues into the biomedical curriculum offers a strategy to overcome student as well as staff resistance (Beck Weiss et al. 2000; Verdonk et al. 2005). The dissemination of research literature to medical teachers can be part of a strategy to implement gender issues. However, providing gender-specific education material such as problem-based cases or audio-visual material and concrete recommendations to their own teaching material offer a better opportunity for integration (Verdonk et al. 2005, 2006; Mans et al. 2005, 2006). Education material helps to convince those who do not think gender has importance to medical education-by clarifying what is meant with integrating gender-or those who experience time and money constraints. Staff education is also important. Several studies exposed that women are more aware of gender than men, for instance among graduate students in education, medical students and staff in medical schools (Hansman et al. 1999; Verdonk et al. 2007a; Risberg et al. 2003, 2004; Hamberg and Johansson 2006). The active participation of men in discussing gender issues in medical education as well as the conscious leadership of senior academic women may prevent the maintenance of the status quo where gender issues are regarded as of secondary 
importance (Wainer 2003; Westerståhl et al. 2003; Risberg et al. 2003; Hamberg and Johansson 2006; Verdonk 2007). Certainly, meetings about curricular gaps in gender issues with faculty leadership and course organizers is productive (Verdonk et al. 2005; Verdonk et al. 2006).

So far, we have focused on curricular change. However, gender issues relevant to students and staff themselves need to be addressed as well. Overall, medical education fails to recognise the salience of social categories by encouraging students to see themselves as socially neutral doctors (Beagan 2000). In spite of the assumption that doctors have no social identity, for instance female and male students do not necessarily have the same ideas about characteristics of the ideal physician (Verdonk et al. 2007b). Besides, harassment and gender stereotyping still detract from women medical students' opportunities and education (Bickel 2001). Studies from Australia, the Netherlands, Finland and Sweden revealed that sexual harassment is still a widespread phenomenon in medical education, which is more often encountered by female students and negatively affects their psychological well-being (Eyres White 2000; van den Muijsenbergh and Lagro-Janssen 2005; Rautio et al. 2005; Larsson et al. 2003). Female physicians encounter types of contrapower harassment by patients that are unique to medical practice and medical education insufficiently prepares for these troubling situations; to some patients, the gender of the physician is more salient than occupational status, and female physicians' sense of responsibility as a caretaker hampers them to take action against harassers (Schneider and Phillips 1997). Currently, sex discrimination also begins to occur against male health providers. Although in academic obstetrics/gynaecology leadership positions are still difficult to reach for women, the belief is increasing that women are more qualified to be obstetrician/gynaecologists because women share unique experiences (Adams 2003). This may result in the exclusion of men as obstetrician/gynaecologists. Additionally, men nurses face contradictory and complex situations of acceptance, mainly because the stereotype of men as sexual aggressors creates suspicion in situations where there is intimate touching (Evans 2002). Furthermore, gender plays a role in specialty choice (Reichenbach and Brown 2004; Johansson and Hamberg 2007).

\section{Programme effectiveness}

Sensitizing programmes result in positive attitude change in students. An evaluation of gender sensitivity in graduate students in education exposed that after specifically tailored courses, students' attitudes towards gender equality were more favourable (Hansman et al. 1999). These findings also apply to students' attitudes after taking women's studies courses in psychology curricula (Case 2007; Yoder et al. 2007). Despite the fact that initially, groups differed in attitudes towards gender issues and gender equality, gender awareness increased in psychology students who followed gender sensitizing programme (Yoder et al. 2007). Furthermore, gender sensitizing courses may have an empowering effect on students themselves (Yoder et al. 2007). These studies evaluated the separate course model: elective or lone-standing courses in gender issues which are often unattractive to male students. Unfortunately, evaluations of the integrated model in medical educationor elsewhere-have hardly been conducted. In the Netherlands, a gender mainstreaming project was conducted from 2002 to 2005 in order to integrate gender health issues in all eight medical curricula. The evaluation of a project in one school revealed that gender can be successfully implemented when for instance (Verdonk et al. 2005): (1) concrete and directly executable recommendations are offered; (2) an enthusiastic trigger person within 
the faculty keeps gender issues on the agenda; (3) recommendations are firmly embedded within the existing programme; (4) course organizers are involved in decision-making, and; (5) practical support is offered.

\section{Conclusion}

Although presently a large body of evidence exposed gender differences in health and illness, gender bias still shapes: (1) the way patients' needs are met; (2) the coverage of gender issues in medical curricula; (3) definitions of diseases; (4) research topics; (5) coverage of issues in research and journals; as well as; (6) the segregation of male and female doctors in medical specialties and their prestige within the profession. Gender bias is also exposed in the shaping practice of making women different from or similar to men; depending on the circumstances, women are treated as reproductive beings or as bodies similar to those of men (Weisman 2000). This is an important issue exposing gender bias as an active, ongoing process instead of a historical deficit that can be resolved by increasing numbers of female doctors or by adding women's health issues to the existing medical curriculum. But equity is not a spontaneous process (Bickel 2001). Social change is a necessity and the burden of change needs to be put on health professionals, not on patients (Lorber and Moore 2002).

Gender issues in health and illness need to be addressed in future doctors' training. By creating awareness of gender differences and gender inequalities as determinants of health, especially medical education can make a (gender) difference in medicine. Successful implementation projects of gender issues in medical education deal with faculty and student resistance, clarify the domain, and offer practical assistance for the integration of gender. Innovative assessment in attitude training will be necessary to measure the values, attitudes, and skills of gender sensitive future doctors (Wong 1998). Gender issues must be well defined and incorporate biopsychosocial aspects, tailored to specific settings, and the dissemination needs to be advocated by faculty leadership (Verdonk et al. 2005). Simultaneously, traditionalists - not necessarily faculty leaders, yet often senior staff-are often perceived to be major obstacles for the implementation of gender issues, which poses specific challenges to implementation. Their maintenance of a reductionist perspective on medicine easily disappears gender from many health problems (Henrich 2004; Verdonk et al. submitted). Guidelines, incentives and disincentives, and audits need to be developed for a structural embedding of gender in medical education. If gender expertise within the faculty is unavailable, schools should be able to consult external experts. And last but not least, a curriculum is not gender-specific if the uptake of gender issues are not guarded by experts with a visible as well as valued place in medical school. Furthermore, successful implementation is not enough, for gender may again disappear from the curriculum (Sen et al. 2002). The monitoring of gender issues is necessary to warrant longitudinal genderspecific curricula.

Future doctors need the opportunity to discuss gender issues of importance to themselves, such as the opportunities within the medical profession and gender segregation within specialties, the glass ceiling, or male physicians' wish to take up care responsibilities. Role modelling by faculty, with male faculty also taking up their duty to advocate gender awareness to medical students, must be of specific concern. And last but not least, it is up to faculty leadership to decide whether young physicians work in organisations with established policies for gender mainstreaming in health care and for workplace issues such as sexual harassment. Aspects of gender at all levels of the health care system need to be 
incorporated into medical education. An investment in medical education is legitimized by future benefits for future patients, and puts responsibility on medical schools to actively reflect on this future.

Open Access This article is distributed under the terms of the Creative Commons Attribution Noncommercial License which permits any noncommercial use, distribution, and reproduction in any medium, provided the original author(s) and source are credited.

\section{References}

Adams, K. E. (2003). Patient choice of provider gender. Journal of the American Medical Women's Association, 58, 117-119.

Adams, A., Buckingham, C. D., Lindenmeyer, A., McKinlay, J. B., Link, C., Marceau, L., \& Arber, S. (2007). The influence of patient and doctor gender on diagnosing coronary heart disease. Sociology of Health \& Illness (in press). DOI: 10.1111/j.1467-9566.2007.01025.x.

Album, D., \& Westin, S. (2008). Do diseases have a prestige hierarchy? A survey among physicians and medical students. Social Science and Medicine, 66, 182-188.

Alexanderson, K., Wingren, G., \& Rosdahl, I. (1998). Gender analyses of medical textbooks on dermatology, epidemiology, occupational medicine and public health. Education for Health, 11, 151-163.

APGO (n.d.). Women's health care competencies for medical students. Retrieved December 19, 2005, from Association of Professors of Gynaecology and Obstetrics and Women's Health Care Education Office website: http://wheocomp.apgo.org/.

Beagan, B. L. (2000). Neutralizing differences: Producing neutral doctors for (almost) neutral patients. Social Science and Medicine, 51, 1253-1265.

Bebbington, P. (1996). The origins of sex differences in depressive disorder: Bridging the gap. International Review of Psychiatry, 8, 295-332.

Beck Weiss, L., Lee, S., \& Levison, S. P. (2000). Barriers and solutions to implementing a new curriculum: Lessons from the women's health education program at MCP Hahnemann School of Medicine. Journal of Women's Health and Gender-Based Medicine, 9, 153-160.

Beck Weiss, L., \& Levison, S. P. (2000). Tools for integrating women's health into medical education: Clinical cases and concept mapping. Academic Medicine, 75, 1081-1086.

Bekker, M. H. J. (2003). Investigating gender within health research is more than sex disaggreggation of data: A multi-facet gender and health model. Psychology, Health \& Medicine, 8, 232-243.

Benrud, L. M., \& Reddy, D. M. (1998). Differential explanations of illness in women and men. Sex Roles: A Journal of Research, 38, S375-S386.

Betancourt, J. R., Green, A. R., Carillo, J. E., \& Ananeh-Firempong, O. (2003). Defining cultural competence: A practical framework for addressing racial/ethnic disparities in health and health care. Public Health Reports, 118, 293-302.

Bickel, J. (2001). Gender equity in undergraduate medical education: A status report. Journal of Women's Health \& Gender Based Medicine, 10, 261-270.

Bird, C. E., \& Rieker, P. P. (1999). Gender matters: An integrated model for understanding men's and women's health. Social Science and Medicine, 48, 745-755.

Bowker, L. (2001). Terminology and gender sensitivity: A corpus-based study on the LSP of infertility. Language in Society, 30, 589-610.

Brodkey, A. C., \& Shaw, D. L. (2002). Women's health competencies in the undergraduate psychiatry curriculum: Past and future. American Journal of Obstetrics and Gynecology, 187, S15-S18.

Brouns, M. (1995). Kernconcepten en debatten. In M. Brouns, M. Verloo, \& M. Grünell (Eds.), Vrouwenstudies in de jaren negentig. Een kennismaking vanuit verschillende disciplines (pp. 29-51). Bussum: Coutinho (Major concepts and debates. In: Women's Studies in the nineties. A multidisciplinary introduction.).

Bylund, C. L., \& Makoul, G. (2002). Empathic communication and gender in the physician-patient encounter. Patient Education and Counseling, 48, 207-216.

Case, K. A. (2007). Raising male privilege awareness and reducing sexism: An evaluation of diversity courses. Psychology of Women Quarterly, 31, 426-435.

Chiaramonte, G. R., \& Friend, R. (2006). Medical students' and residents' gender bias in the diagnosis, treatment, and interpretation of coronary heart disease. Health Psychology, 25, 255-266.

Christianson, M., Lalos, A., \& Johansson, E. E. (2007). Concepts of risk among young Swedes tested negative for HIV in primary care. Scandinavian Journal of Primary Health Care, 25, 38-43. 
Clark, J. P., Feldberg, G. D., \& Rochon, P. A. (2002). Representation of women's health in general medical versus women's health specialty journals: A content analysis. BMC Women's Health, 2, 5. Retrieved January 14, 2008, from http://www.biomedcentral.com/1472-6874/2/5.

Courtenay, W. H. (2000). Constructions of masculinity and their influence on men's well-being: A theory of gender and health. Social Science \& Medicine, 50, 1385-1401.

Davis, K. (1988). Power under the microscope. Toward a grounded theory of gender relations in medical encounters. Dissertation, Free University Amsterdam.

Davis-Russel, E. (2003). Integrating multicultural issues into graduate clinical psychology training. In P. Bronstein \& K. Quina (Eds.), Teaching gender and multicultural awareness. resources for the psychology classroom (pp. 339-346). Washington DC: American Psycological Association.

Donoghue, G. D. (2000). Introduction. Women's health: A catalyst for reform of medical education. Academic Medicine, 75, 1056-1060.

Doyal, L. (1995). What makes women sick? Gender and the political economy of health. New Jersey: Rutgers University Press.

Doyal, L. (2000). Gender equity in health: Debates and dilemmas. Social Science \& Medicine, 51, 931-939.

Doyal, L., Payne, S., \& Cameron, A. (2003). Promoting gender equality in health. Manchester: Equal Opportunities Commission. Retrieved September 26, 2006, from Equality and Human Rights Commission website: http://www.eoc.org.uk/PDF/promoting_gender_equality_in_health.pdf.

Evans, J. A. (2002). Cautious caregivers: Gender stereotypes and the sexualization of men nurses' touch. Journal of Advanced Nursing, 40, 441-448.

Eyres White, G. (2000). Sexual harassment during medical training: The perceptions of medical students at a university medical school in Australia. Medical Education, 34, 980-986.

Fausto-Sterling, A. (2000). Beyond difference. Feminism and evolutionary psychology. In H. Rose \& S. Rose (Eds.), Alas, poor Darwin. Arguments against evolutionary psychology (pp. 209-227). New York: Harmony Books.

Foss, C., \& Sundby, J. (2003). The construction of the gendered patient: Hospital staff's attitudes to female and male patients. Patient Education and Counseling, 49, 45-52.

Gender and Health Collaborative Curriculum Project (n.d.). Retrieved September 21, 2006, from Ontario Women's Health Counsil website: http://www.genderandhealth.ca/.

Gijsbers van Wijk, C. M. T., van Vliet, K. P., \& Kolk, A. M. (1996). Gender perspectives and quality of care: Towards appropriate and adequate health care for women. Social Science and Medicine, 43, 707-720.

Hall, J. A., \& Roter, D. L. (1998). Medical communication and gender: A summary of research. The Journal of Gender-Specific Medicine, 1, 39-42.

Hamberg, K., \& Johansson, E. E. (2006). Medical students' attitudes to gender issues in the role and career of physicians: A qualitative study conducted in Sweden. Medical Teacher, 28, 635-641.

Hammarström, A. (2003). The integration of gender in medical research, education-Obstacles and possibilities from a Nordic perspective. In L. Manderson (Ed.), Teaching gender, teaching women's health. Case studies in medical and health science education (pp. 121-133). Binghamton: The Haworth Medical Press.

Hammarström, A. (2007). A tool for developing gender research in medicine: Examples from the medical literature on work life. Gender Medicine, 4(Suppl B), S123-S132.

Hansman, C. A., Jackson, M., Grant, D., \& Spencer, L. (1999). Assessing graduate students' sensitivity to gender, race, equality and diversity: Implications for curriculum development. College Student Journal, 33, 261-268.

Henrich, J. B. (2004). Women's health education initiatives: Why have they stalled? Academic Medicine, 79, 283-288

Hoffman, E. (2000). Women's health and complexity science. Academic Medicine, 75, 1102-1106.

Hoffman, E., Magrane, D., \& Donoghue, G. D. (2000). Changing perspectives on sex and gender in medical education. Academic Medicine, 75, 1051-1055.

Horstman, K. (1995). Het (vrouwelijk) lichaam en het beeld. In M. Brouns, M. Verloo, \& M. Grünell (Eds.), Vrouwenstudies in de jaren negentig. Een kennismaking vanuit verschillende disciplines (pp. 109134). Bussum: Coutinho (The (female) body and the image. In Women's Studies in the nineties. A multidisciplinary introduction.).

Im, E.-O., \& Meleis, A. I. (2001). An international imperative for gender-sensitive theories in women's health. Journal of Nursing Scholarship, 33, 309-314.

Jimenez, C., \& Poniatowski, B. (2004). Workshop on gender and health. Report. Tokyo: 27 and 28 October 2004. Retrieved September 26, 2006, from United Nations University website: http://www.unu.edu/ misc/GenderHealth-report.pdf.

Johansson, E. E., \& Hamberg, K. (2007). From calling to a scheduled vocation: Swedish male and female students' reflections on being a doctor. Medical Teacher, 29, e1-e8. 
Kilmartin, C. (2005). Depression in men: Communication, diagnosis and therapy. Journal of Men's Health and Gender, 2, 96-99.

Kiss, A., \& Meryn, S. (2001). Effect of sex and gender on psychosocial aspects of prostate and breast cancer. British Medical Journal, 323, 1055-1058.

Lagro-Janssen, T., \& Noordenbos, G. (Eds.) (1997). Sekseverschillen in ziekte en gezondheid. Nijmegen: SUN (Gender differences in illness and health.).

Larsson, C., Hensing, G., \& Allebeck, P. (2003). Sexual and gender-related harassment in medical education and research training: Results from a Swedish study. Medical Education, 37, 39-50.

Lie, M. (2002). Science as father? Sex and gender in the age of reproductive technologies. The European Journal of Women's Studies, 9, 381-399.

Lorber, J., \& Moore L. J. (2002). Gender and the social construction of illness (2nd ed.). Oxford: Altamira Press.

Macintyre, S., Hunt, K., \& Sweeting, H. (1996). Gender differences in health: Are things really as simple as they seem? Social Science and Medicine, 42, 617-624.

Magrane, D., Ephgrave, K., Jacobs, M. B., \& Rusch, R. (2000). Weaving women's health across clinical clerkships. Academic Medicine, 75, 1066-1070.

Mans, L., Dijkstra, A., \& Lagro-Janssen, T. (2005). Sekse en diversiteit in het professioneel handelen. 50 patiëntencasus voor het medisch onderwijs. Nijmegen: Radboud University Nijmegen Medical Centre, Women's Studies in Medicine (Gender and diversity in professionalism. 50 clinical cases for medical education.).

Mans L. J. L., Verdonk, P., \& Lagro-Janssen, A. L. M. (2006). De rol van het Digitaal Kenniscentrum Seksespecifiek Medisch Onderwijs bij de integratie van sekse in het medisch onderwijs. Tijdschrift voor Medisch Onderwijs, 25, 66-74 (The role of the Digital Knowledge Centre Gender-specific Medical Education in the integration of gender in medical education.).

Mansfield, A. K., Addis, M. E., \& Mahalik, J. R. (2003) "Why won't he go to the doctor?": The psychology of men's help seeking. International Journal of Men's Health, 2, 93-110.

Mosca, L., Banka, C. L., Benjamin, E. J., Berra, K., Bushnell, C., Dolor, R. J., et al. (2007). Evidence-based guidelines for cardiovascular disease prevention in women: 2007 update. Circulation, 115, 1481-1501.

Moynihan, C. (1998). Theories in health care and research: Theories of masculinity. British Medical Journal, 317, 1072-1075.

Nicolette, J., \& Jacobs, M. B. (2000). Integration of women's health into an internal medicine core curriculum for medical students. Academic Medicine, 75, 1061-1062.

Noordenbos, G. (2007). Worden mannen over het hoofd gezien? Sekseverschillen in de diagnostiek en behandeling van depressie. Tijdschrift voor Genderstudies, 10, 16-28 (Are men overlooked? Sex differences in diagnostic and treatment of depression.).

Phillips, S. P. (2005). Defining and measuring gender: A social determinant of health whose time has come. Internal Journal for Equity in Health, 4, 11. Retrieved August 16, 2005, from http://www. equityhealthj.com/content/4/1/11.

Phillips, S. P., \& Ferguson, K. E. (1999). Do student's attitudes toward women change during medical school? Canadian Medical Association Journal, 160, 357-361.

Pinn, V. W. (2003). Sex and gender factors in medical studies. Implications for health and clinical practice. Journal of the American Medical Association, 289, 397-400.

Rautio, A., Sunnari, V., Nuutinen, M., \& Laitala, M. (2005). Mistreatment of university students most common during medical studies. BMC Medical Education, 5, 36. Retrieved December 17, 2007 from http://www.biomedcentral.com/1472-6920/5/36/abstract.

Reichenbach, L., \& Brown, H. (2004). Gender and academic medicine: Impacts on the health workforce. BMJ, 329, 792-795.

Risberg, G., Hamberg, K., \& Johansson, E. (2003). Gender awareness among physicians-The effect of specialty and gender. A study of teachers at a Swedish medical school. BMC Medical Education, $3,8$. Retrieved December 17, 2007 from http://www.biomedcentral.com/1472-6920/3/8.

Risberg, G., Johansson, E., Westman, G., \& Hamberg, K. (2004). Gender in medicine-An issue for women only? A survey of physician teachers' gender attitudes. International Journal for Equity in Health, 2 , 10. Retrieved December 13, 2007 from http://www.equityhealthj.com/content/2/1/10.

Rogers, N., \& Henrich, J. B. (2003). Teaching women's health into the 21st Century. Women \& Health, 37, 11-21.

Rosser, S. V. (1994). Women's health-Missing from U.S. medicine. Bloomington/Indianapolis: Indiana University Press.

Ruiz, M. T., \& Verbrugge, L. M. (1997). A two way view of gender bias in medicine. Journal of Epidemiology and Community Health, 51, 106-109. 
Sabo, D. (1999). Understanding men's health: A relational and gender sensitive approach. Harvard Center for Population and Development Studies. Working Paper Series Number 99.14. Retrieved 21 September 2006 from Harvard School of Public Health website: http:/www.hsph.harvard.edu/ Organizations/healthnet/HUpapers/gender/sabo.html.

Schneider, M., \& Phillips, S. P. (1997). A qualitative study of sexual harassment of female doctors by patients. Social Science and Medicine, 45, 669-676.

Searle, J. (1998). Introduction of a new curriculum in women's health in medical education: A Framework for change. Women's Health Issues, 8, 382-388.

Sen, G., George, A., \& Östlin, P. (2002). Engendering health equity: A review of research and policy. Harvard Center for Population and Development Studies. Working Paper Series Volume 11 Number 2 [on-line]. Retrieved 26 September 2006 from Harvard Initiative for Global Health website: http://www.globalhealth.harvard.edu/hcpds/wpweb/Senwp1202.pdf.

Stevens, I., \& van Lamoen, I. (2001). Manual on gender mainstreaming at universities. 'Equal opportunities at universities. Towards a gender mainstreaming approach'. Leuven-Apeldoorn: Garant, Katholieke Universiteit Leuven en Centrum voor Gender en Diversiteit Universiteit Maastricht.

Taylor, S. E., Cousino Klein, L., Lewis, B. P., Gruenewald, T. L., Gurung, R. A. R., \& Updegraff, J. A. (2000). Biobehavioral responses to stress in females: Tend-and-befriend, not fight-or-flight. Psychological Review, 3, 411-429.

Titus, J. J. (2000). Engaging student resistance to feminism: 'How is this stuff going to make us better teachers?' Gender and Education, 12, 21-37.

UN (1995). Report of the Fourth World Conference on Women. Beijing, United Nations [On-line]. Retrieved September 26, 2006, from United Nations website: http://www.un.org/esa/gopher-data/conf/ fwcw/off/a-20.en.

UN (2002). Gender mainstreaming. An overview. New York: United Nations.

van den Muijsenbergh, M. E. T. C., \& Lagro-Janssen, A. L. M. (2005). Seksuele intimidatie van coassistenten tijdens hun stage. Nederlands Tijdschrift voor Geneeskunde, 149, 764-768 (Sexual harrassment of medical students during their period of work placement.).

van Mens-Verhulst, J., \& Moerman, C. (2002). Seksebewust epidemiologisch onderzoek. TSG tijdschrift voor gezondheidswetenschappen, 80, 219-230 (Gender aware epidemiology research.).

Verdonk, P. (2007). Gender matters in medical education. Integrating a gender perspective in medical curricula. Dissertation, Nijmegen: Radboud University Nijmegen Medical Centre.

Verdonk, P., Benschop, Y. W. M., de Haes, J. C. J. M., \& Lagro-Janssen, A. L. M. (2007a). Medical students' gender awareness. Construction of the Nijmegen Gender Awareness in Medicine Scale (NGAMS). Sex Roles (in press). DOI: 10.1007/s11199-007-9326-x.

Verdonk, P., Harting, A., \& Lagro-Janssen, T. (2007b). Does equal education generate equal attitudes? Gender differences in medical students' attitudes toward the ideal physician. Teaching and Learning in Mecicine, 19, 9-13.

Verdonk, P., Mans, L. J. L., \& Lagro-Janssen, A. L. M. (2005). Integration of the factor gender into a basic medical curriculum. Medical Education, 39, 1118-1125.

Verdonk, P., Mans, L. J. L., \& Lagro-Janssen, A. L. M. (2006). How is gender integrated in the curricula of Dutch medical schools? A quick-scan on gender issues as an instrument for change. Gender and Education, 18, 399-412.

Wainer, J. (2003). Gender and the medical curriculum: A rural case study. Women \& Health, 37, 67-87.

Weisman, C. (2000). The trends in health care delivery for women: Challenges for medical education. Academic Medicine, 75, 1107-1113.

Westerståhl, A., Andersson, M., \& Söderström, M. (2003). Gender in medical curricula: Course organizer views of a gender-issues perspective in medicine in Sweden. Women \& Health, 37, 34-47.

White, A., \& Cash, K. (2004). The state of men's health in Western Europe. The Journal of Men's Health \& Gender, 1, 60-66.

WHO (2001). Madrid Statement. Mainstreaming gender equity in health: The need to move forward. Spain: Madrid, 14 September 2001. Retrieved December 17, 2007, from World Health Organisation website: http://www.euro.who.int/document/a75328.pdf.

WHO (2002). WHO gender policy: Integrating gender perspectives in the work of WHO. Geneva: World Health Organisation. Retrieved September 26, 2006, from World Health Organisation website: http://www.who.int/gender/documents/engpolicy.pdf.

Wong, Y.-L. (1998). Integrating the gender perspective in medical and health education and research. Conference Discussion Paper Expert Group Meeting on Women and Health. Mainstreaming the Gender Perspective into the Health Sector. Tunis: United Nations. Retrieved September 21, 2006, from United Nations website: http://www.un.org/womenwatch/daw/csw/integrate.htm. 
Yoder, J. D., Fischer, A. R., Kahn, A. S., \& Groden, J. (2007). Changes in students' explanations for gender differences after taking a psychology of women class: More constructionist and less essentialist. Psychology of Women Quarterly, 31, 415-425.

Zelek, B., Phillips, S. P., \& Lefebvre, Y. (1997). Gender sensitivity in medical curricula. Canadian Medical Association Journal, 156, 1297-1300.

Zimmerman, M. K., \& Hill, S. A. (2000). Reforming gendered health care: an assessment of change. International Journal of Health Services, 30, 771-795. 